\title{
Asymmetric three-component domino reaction: an original access to chiral nonracemic 1,3-thiazin-2-ones
}

\section{Flavie Peudru, ${ }^{a}$ Fabien Le Cavelier, ${ }^{a}$ Jean-François Lohier, ${ }^{a}$ Mihaela Gulea*a,b and Vincent Reboul*a $^{\star}$}

${ }^{a}$ Laboratoire de Chimie Moléculaire et Thioorganique, UMR 6507 CNRS,

INC3M, FR 3038, ENSICAEN, Université de Caen Basse Normandie, 6 Bd. Maréchal Juin, 14050 Caen, France.

${ }^{b}$ Laboratoire d'Innovation Thérapeutique, UMR 7200 CNRS-Université de Strasbourg, Faculté de Pharmacie, 74 route du Rhin B.P. 24, 67401 Illkirch Cedex, France.

gulea@unistra.fr; vincent.reboul@ensicaen.fr

Received Date (will be automatically inserted after manuscript is accepted)<smiles></smiles>

A new asymmetric three-component domino process, based on a diastereoselective hetero-Diels-Alder reaction, involving an aldehyde, an alkene, and a chiral thiocarbamate was developed. The chiral auxiliary is directly removed during this process, leading to enantioenriched $2 H-1,3$-thiazin-2-ones with up to $96 \%$ ee.

Multicomponent reactions (MCRs) represent a powerful strategy in diversity oriented synthesis of heterocycles, which are compounds of outstanding importance for pharmaceutical and agrochemical industries. ${ }^{1}$ In these two fields, interest for the synthesis of such compounds in optically pure form has prompted the development of asymmetric versions of existing or new MCRs. ${ }^{2}$

Several asymmetric multicomponent reactions based on the hetero-Diels-Alder (HDA) reaction have been described, mainly involving imine partners ${ }^{1 \mathrm{~b}, 3}$ and

1 (a) Biggs-Houck, J. E.; Younai, A.; Shaw, J. T. Curr. Op. Chem. Biol. 2010, 14, 371. (b) Choudhury, L. H.; Parvin, T. Tetrahedron 2011, 67, 8213. (c) Eckert, H. Molecules 2012, 17, 1074.

2 (a) Ramón, D. J.; Yus, M. Angew. Chem., Int. Ed. 2005, 44, 1602. (b) de Graaff, C.; Ruijter, E.; Orru, R. V. A. Chem. Soc. Rev. 2012, 41, 3969.

${ }^{3}$ For reviews in imine-based HDA reactions, see: (a) Weinreb, S. M.; Scola, P. M. Chem. Rev. 1989, 89, 1525. (b) Boger, D. L. Tetrahedron therefore leading to chiral six-membered $N$-heterocycles. However, only a few examples have been applied to the synthesis of heterocycles containing two heteroatoms.

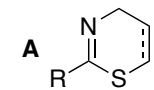

$4 H$-1,3-thiazine

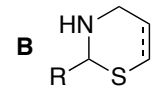

$2 \mathrm{H}$-1,3-thiazine
C

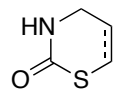

2H-1,3-thiazin-2-one
Figure 1. 1,3-Thiazine scaffolds

1983, 39, 2869. (c) Buonora, P.; Olsen, J.; Oh, T. Tetrahedron 2001, 57, 6099. (d) Jayakumar, S.; Ishar, M. P. S.; Mahajan, M. P. Tetrahedron 2002, 58, 379. (e) Li, J.-L.; Liu, T.-Y.; Chen, Y.-C. Acc. Chem. Res 2012, 45, 1491. (f) Masson, G.; Lalli, C.; Benohoud, M.; Dagousset, G. Chem. Soc. Rev. 2013, 42, 902. (g) Jiang, X.; Wang, R. Chem. Rev. 2013, 113, 5515 . 
1,3-Thiazines A-B (Fig. 1) are attractive six-membered $N, S$-heterocyclic scaffolds for medicinal chemistry. ${ }^{4}$ Compounds bearing this subunit often exhibit valuable biological activities ${ }^{5}$ and are also used as precursors for the preparation of other heterocyclic biomolecules, such as cephalosporins or 1,4-thiazepines. ${ }^{6}$ Nevertheless, to the best of our knowledge, only two methods for the asymmetric synthesis of optically active 1,3-thiazines have been reported so far. ${ }^{7,8}$ Moreover, the chemistry and biological activities of 1,3-thiazin-2-one $\mathbf{C}$ (Fig. 1) were much less studied probably due to the lack of general method to synthesize them. Indeed, only two methods for their preparation in achiral series are reported. ${ }^{9}$ Thus, an asymmetric three-component reaction (3CR) route to access a large variety of 1,3-thiazine structures ${ }^{10}$ is a noteworthy development in the MCR community.

Scheme 1. Proposed asymmetric synthesis of 1,3-thiazin-2-ones

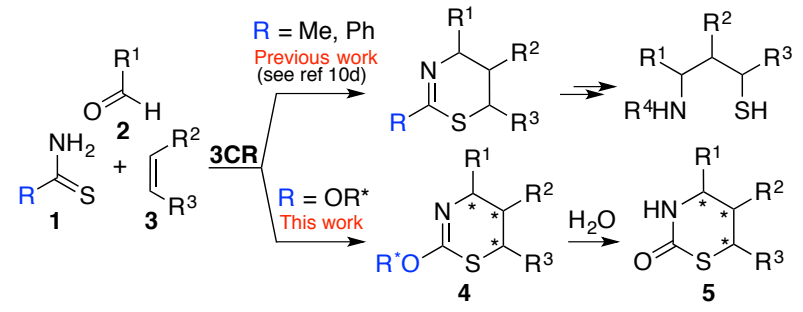

4 (a) Quiniou, H.; Guilloton, O. 1,3-Thiazines. In Adv. Heterocycl. Chem.; Katritzky, A. R., Ed. 1990; Vol. 50, pp 85-156. (b) Fülöp, F.; Bernáth, G.; Pihlaja, K. Synthesis, Stereochemistry and Transformations of Cyclopentane-, Cyclohexane-, Cycloheptane-, and CyclooctaneFused 1,3-Oxazines, 1,3-Thiazines, and Pyrimidines. ibid. 1997; Vol. 69, pp 349-477. (c) Hermecz, I. Chemistry of Pyrido[2,1c][1,4] oxazines, Pyrido[2,1-c][1,4]thiazines, Pyrido[1,2-a]pyrazines and Their Benzologues. ibid. 1998; Vol. 71, pp 145-289. (d) Schmidt, R. R. Synthesis-Int. J. Meth. Synth. Org. Chem. 1972, 7, 333.

5 (a) Torres-García, P.; Viñuelas-Zahínos, E.; Luna-Giles, F.; Espino, J.; Barros-García, F. J. Polyhedron 2011, 30, 2627. (b) Thanusu, J.; Kanagarajan, V.; Gopalakrishnan, M. J. Enz. Inhib. Med. Chem. 2010, 25, 756. (c) Fu, L.; Ye, D.; Li, Y.; Yin, S. Chem. Natural Compounds 2010, 46, 169. (d) Nayak, J.; Girisha, K. S.; Kalluraya, B.; Shenoy, S. Phosphorus, Sulfur Silicon Relat. Elem. 2009, 184, 2697.

6 (a) Demain, A. L.; Sanchez, S.-T. J. Antibiot. 2009, 62, 5. (b) Fodor, L.; Csomós, P.; Károlyi, B.; Csámpai, A.; Sohár, P. Arkivoc 2012, part (v), 37. (c) Fodor, L.; Csomós, P.; Csámpai, A.; Sohár, P.; Holczbauer, T.; Kálmán, A. Tetrahedron Lett. 2011, 52, 592. (d) Fodor, L.; Csomós, P.; Holczbauer, T.; Kálmán, A.; Csámpai, A.; Sohár, P. Tetrahedron Lett. 2011, 52, 224. (e) Fodor, L.; Csomós, P.; Csámpai, A.; Sohár, P. Synthesis 2010, 2943.

7 For the synthesis of 5,6-dihydro-4H-1,3-thiazine by asymmetric HDA reaction, see: (a) Marchand, A.; Mauger, D.; Guingant, A.; Pradère, J. Tetrahedron: Asymmetry 1995, 6, 853. (b) HarrisonMarchand, A.; Collet, S.; Guingant, A.; Pradère, J.-P.; Toupet, L. Tetrahedron 2004, 60, 1827.

8 For the synthesis of 1,3-thiazine-2,4-diones by rearrangement of chiral $\mathrm{N}$-enoyl oxazolidinethiones, see: (a) Hernández, H.; Bernès, $\mathrm{S}$. Quintero, L.; Sansinenea, E.; Ortiz, A. Tetrahedron Lett. 2006, 47, 1153. (b) Ortiz, A.; Quintero, L.; Mendoza, G.; Bernès, S. Tetrahedron Lett. 2003, 44, 5053.

9 (a) Sonoda, N.; Yamamoto, G.; Natsukawa, K.; Kondo, K.; Murai, S. Tetrahedron Lett. 1975, 16, 1969. (b) Dong, C.; Alper, H. Org. Lett. 2004, 6,3489

10 (a) Abis, L.; Giordano, C. J. Chem. Soc. Perkin Trans. 1 1973, 771. (b) Zhu, Y.; Huang, S.; Wan, J.; Yan, L.; Pan, Y.; Wu, A. Org. Lett. 2006, 8, 2599. (c) Wan, J.-P.; Pan, Y.-H.; Mao, H.; Chen, Y.-H.; Pan, Y.-J. Synth. Commun. 2010, 40, 709. (d) Peudru, F.; Legay, R.; Lohier, J.-F.; Reboul, V.; Gulea, M. Tetrahedron 2012, 68, 9016.
We recently reported the racemic synthesis of new $4 H-$ 1,3-thiazines via a 3CR of thioamides $(\mathrm{R}=\mathrm{Me}, \mathrm{Ph})$, aldehydes, and alkenes, and one application to access $\gamma$ aminothiols (Scheme 1). ${ }^{10 d}$ In the present work, we describe a new asymmetric three components HDA-based reaction, involving a chiral thiocarbamate $\mathbf{1}$ derived from an enantiopure alcohol. We anticipated a facile removing of the chiral auxiliary, by simple hydrolysis of $\mathbf{4}$, leading to enantioenriched 4,6-disubstituted-tetrahydro- $2 \mathrm{H}$-1,3thiazin-2-ones 5 (Scheme 1).

First, we validated the reaction in a racemic series by reacting achiral commercially available $O$-ethyl thiocarbamate $\mathbf{1 a}$, benzaldehyde $\mathbf{2 a}$, and norbornene $\mathbf{3 a}$ or styrene $\mathbf{3 b}$. After the reaction optimization, we found that the use of $\mathrm{BF}_{3} \cdot \mathrm{Et}_{2} \mathrm{O}$ (2 equiv) under $\mathrm{MW}$ irradiation (40 $\mathrm{W} ; 150{ }^{\circ} \mathrm{C}$ ) was necessary to obtain a total conversion after only 10 min. ${ }^{11}$ Interestingly, the expected 2-ethoxy4H-1,3-thiazine derivatives 4 were readily converted in situ to the corresponding 1,3-thiazin-2-ones $\mathbf{5 a}$ and $\mathbf{5 b}$ (Scheme 2) which were obtained in quantitative yields, with high diastereoselectivity: major cycloadduct exo for 5a $(94: 6 \mathrm{dr})$ and endo for $\mathbf{5 b}(92: 8 \mathrm{dr})$. Both of them were isolated as a single diastereoisomer, of which relative stereochemistry was confirmed by X-ray analysis.

Scheme 2. Synthesis of racemic 1,3-thiazin-2-ones $\mathbf{5 a}$ and $\mathbf{5 b}$ and corresponding $\mathrm{X}$-ray structures.

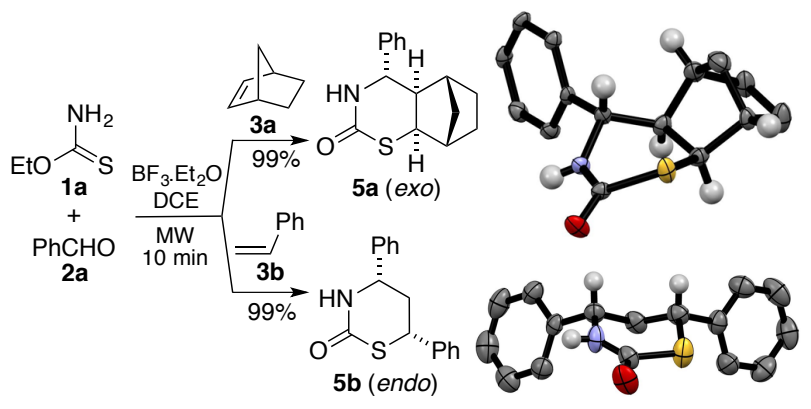

A plausible mechanism of the reaction is depicted in Scheme 3. The $\mathrm{BF}_{3} \cdot \mathrm{Et}_{2} \mathrm{O}$-mediated formation of the thiaazadiene provided one molecule of water, which subsequently underwent a nucleophilic addition to the C2 position of the HDA cycloadduct, ${ }^{12}$ leading to 1,3 thiazin-2-one upon loss of an alcohol. Competitive C-S cleavage with ring opening was not observed.

The direct cleavage of the alcohol moiety prompted us to consider a one-step access to enantioenriched 1,3thiazin-2-ones via an asymmetric three-component domino reaction, using chiral $O$-alkyl thiocarbamates derived from enantiopure alcohols.

\footnotetext{
${ }^{11} \mathrm{BF}_{3}$.THF, $\mathrm{B}\left(\mathrm{C}_{6} \mathrm{~F}_{5}\right)_{3}$ or $\mathrm{Et}_{2} \mathrm{O}$ as solvent lowered the conversion.

${ }^{12}$ Cheng, Y.-S.; Ho, E.; Mariano, P. S.; Ammon, H. L. J. Org. Chem. $\mathbf{1 9 8 5}, 50,5678$
} 
Scheme 3. Plausible mechanism for the formation 5.

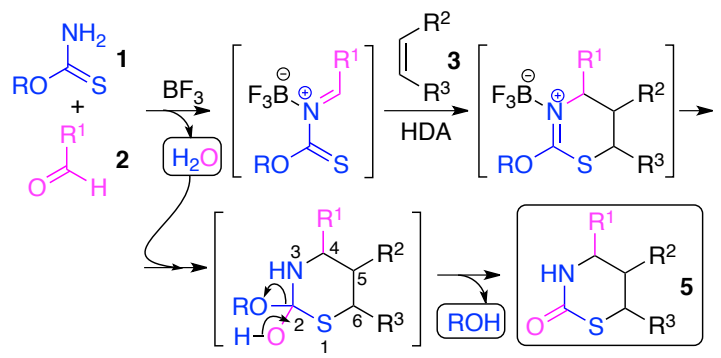

Easily available enantiopure alcohols commonly used as chiral auxiliaries in asymmetric synthesis were selected for this purpose: (-)-1-phenylethanol, diacetone- $D-(-)$ glucose (DAG), (-)-borneol, (-) and (+)-menthol, (-)-8phenylmenthol, ${ }^{13}$ and (-)-8-(2-naphthyl)-menthol. ${ }^{14}$ Chiral primary thiocarbamates $\mathbf{1 b}$-h were prepared in four steps ${ }^{15}$ and good overall yields (Scheme 4).

Scheme 4. Synthesis of $\mathbf{1 b}-\mathbf{h}$; X-ray structure of $\mathbf{1 h}$

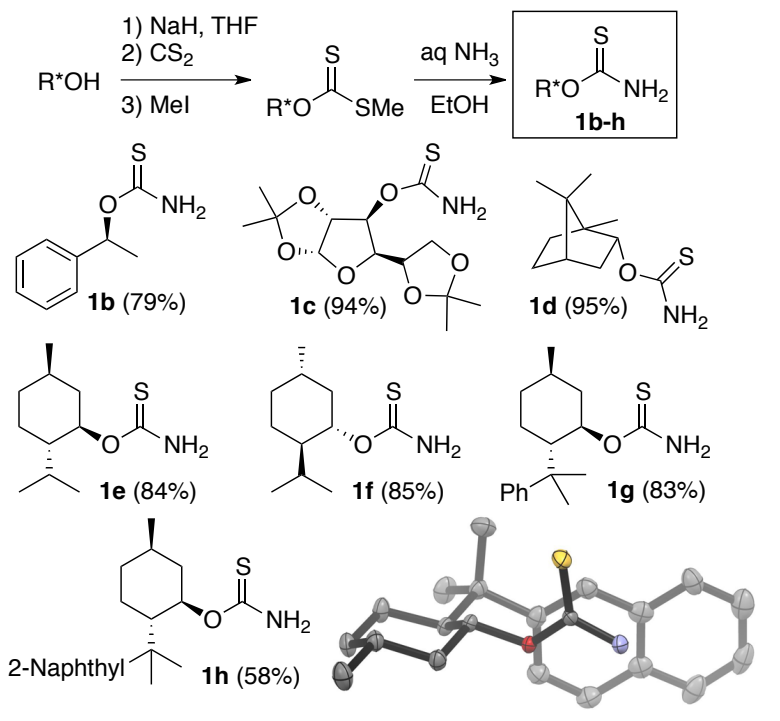

Recrystallization of $\mathbf{1 h}$ in $\mathrm{CHCl}_{3}$ furnished a single crystal for X-ray analysis.

The asymmetric induction of chiral thiocarbamates $\mathbf{1 b}-\mathbf{h}$ was evaluated using dienophiles $\mathbf{3 a}$ and $\mathbf{3 b}$, and benzaldehyde $\mathbf{2 a}$. (Table 1). Surprisingly no reaction occurred with $\mathbf{1 b}$ (entry 1), ${ }^{16}$ but in all the other casses, the expected compound was obtained with good to high stereoselectivity $(76: 24$ to $99: 1 \mathrm{dr})$ and the major

${ }^{13}$ Corey, E. J.; Ensley, H. E. J. Am. Chem. Soc. 1975, 97, 6908.

14 This compound was synthesized from $(R)-(+)$-pulegone: Yang, D.; Xu, M.; Bian, M.-Y. Org. Lett. 2001, 3, 111.

15 Ané, A.; Prestat, G.; Thiam, M.; Josse, S.; Pipelier, M.; Pradère, J.P.; Dubreuil, D. Nucleosides, Nucleotides Nucleic Acids 2002, 21, 335.

16 The thiocarbamate was probably consumed in a polymerisation processes: Sebenik, A. Prog. Polym. Sci. 1998, 23, 875. cycloadduct (exo-5a or endo-5b) was cleanly isolated. Poor enantiomeric ratios were observed by reacting norbornene 3a with thiocarbamates 1c-e (entries 2-5). However, a promising 73:27 er was obtained with the 8phenylmenthol derivative $\mathbf{1 g}$ (entry 5). With styrene $\mathbf{3 b}$ better enantiomeric ratios were obtained (entries 6-11), in particular in menthol thiocarbamate series (entries 8-11). Obviously, enantiomeric menthol thiocarbamates 1e and 1f gave the same ee $(66 \%)$, but opposite asymmetric induction (Entries 8-9).

Table 1. Asymmetric synthesis of 1,3-thiazin-2-ones $\mathbf{5 a}$ and $\mathbf{5} \mathbf{b}^{\mathrm{a}}$

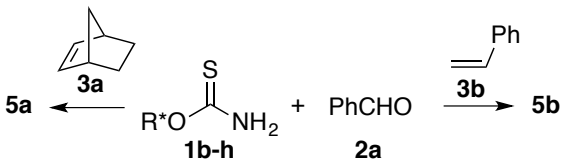

\begin{tabular}{|c|c|c|c|c|c|c|}
\hline entry & $\begin{array}{c}\text { thio- } \\
\text { carbamate }\end{array}$ & alkene & product & $\begin{array}{l}\text { yield } \\
(\%)^{b}\end{array}$ & $\begin{array}{c}\text { endo/exo } \\
\mathrm{dr}^{\mathrm{c}}\end{array}$ & $e^{d}$ \\
\hline 1 & $1 \mathrm{~b}$ & $3 a$ & $5 a$ & - & - & - \\
\hline 2 & $1 \mathrm{c}$ & $3 a$ & $5 a$ & 67 & 1:99 & $56: 44$ \\
\hline 3 & 1d & $3 a$ & $5 a$ & 98 & 7:93 & 59:41 \\
\hline 4 & $1 e$ & $3 a$ & $5 a$ & 98 & 8:92 & $63: 37$ \\
\hline 5 & $1 \mathrm{~g}$ & $3 a$ & $5 a$ & 64 & $6: 94$ & $73: 27$ \\
\hline 6 & $1 c$ & $3 b$ & $5 b$ & 40 & $76: 24$ & $73: 27$ \\
\hline 7 & $1 d$ & $3 b$ & $5 b$ & 94 & $91: 9$ & $61: 39$ \\
\hline 8 & $1 \mathrm{e}$ & $3 b$ & $5 b$ & 89 & $90: 10$ & $83: 17$ \\
\hline 9 & 1f & $3 \mathbf{b}$ & $5 b$ & 96 & $90: 10$ & $17: 83$ \\
\hline 10 & $1 \mathrm{~g}$ & 3b & $5 b$ & 91 & $87: 13$ & $94: 6$ \\
\hline 11 & $1 \mathrm{~h}$ & $3 b$ & $5 b$ & 88 & $92: 8$ & $97: 3$ \\
\hline
\end{tabular}

The best results were obtained with C-8 substituted menthols: 94:6 er with 8-phenyl derivative 1g (entry 10) and $97: 3$ er with the more hindered 8-(2-naphthyl) derivative $\mathbf{1 h}$ (entry 11). The absolute configuration of the major $\mathbf{5 b}$ obtained from $\mathbf{1 e}$ was unambiguously assigned as $(4 S, 6 R)$ by X-ray crystallographic analysis. ${ }^{17}$

Although thiocarbamate $\mathbf{1 h}$ afforded higher er, thiocarbamate $\mathbf{1 g}$ with an acceptable loss of chiral induction, was ultimately selected during the investigation of the reaction scope as 8-phenylmenthol is commercially available. Various substituted styrenes and aldehydes were tested. The results are summarized in Table 2. For chiral HPLC analyses, all the corresponding racemic compounds were prepared from racemic $O$ menthyl thiocarbamate $r a c-1 e^{18}$ (see Table in Supporting Information).

The reaction with $\mathbf{1 g}$ and styrene $\mathbf{3 b}$ worked either with aromatic aldehydes or aliphatic aldehydes ${ }^{19}$ affording 1,3thiazin-2-ones $\mathbf{5 c - e , 5} \mathbf{5 g - i}$ in moderate to high yields (55 to $98 \%$ ) and with very satisfactory enantiomeric ratios

17 A single crystal of the enantiopure compound $\mathbf{5 b}$ (ee $>99 \%$ by chiral HPLC) was obtained from 1e by recrystallization in chloroform and slow evaporation. The Flack parameter from X-ray analysis is 0.01 .

18 rac-1e derived from racemic menthol was used instead of $\mathbf{1 a}$.

${ }^{19}$ No reaction occurred with an alkyl aldehyde when a thioamide was used instead of a thiocarbamate (see ref $10 \mathrm{~d}$ ). 
ranging from 89:11 to $97: 3$ (entries 1-3, 5-7). Only the reaction with 4-methoxybenzaldehyde failed, due probably to a lower reactivity of the aldehyde induced by the electron donating methoxy group towards the sterically hindered thiocarbamate. However, it was possible to prepare compound $\mathbf{5 f}$ from the (+)-menthyl thiocarbamate 1f, in 56\% yield and with 18:82 er (entry 4). Then, $1 \mathbf{g}$ and benzaldehyde $\mathbf{2 a}$ were reacted with 3chlorostyrene and 3-methoxystyrene (entries 8-9), leading to the corresponding cycloadducts $\mathbf{5} \mathbf{j}$ and $\mathbf{5} \mathbf{k}$ with high level of chiral induction (98:2 and 97:3 er, respectively). Although complete endo/exo selectivitites were not achieved (78:22 to $96: 4 \mathrm{dr}$ ), in most of cases the major diastereomer ${ }^{20}$ can be isolated. Phenylacetylene was also tested as the dienophile in reaction with benzaldehyde and thiocarbamate 1f (as no reaction took place with 1g), leading to 3,4-dihydrothiazine-2-one $\mathbf{6}$ in good yield, but with a disappointing er of 53:47 (entry 10).

Table 2. Scope and limitation of asymmetric $3 \mathrm{CR}^{\mathrm{a}}$
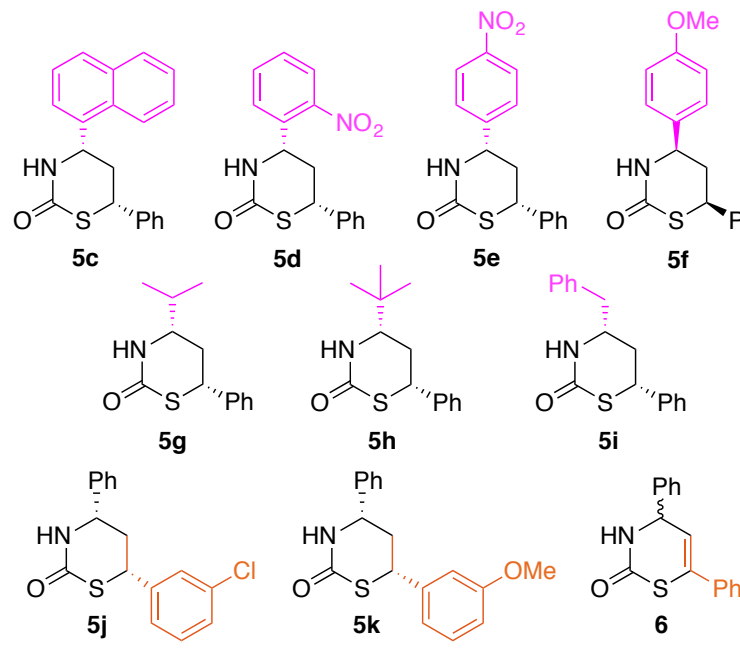

\begin{tabular}{|c|c|c|c|c|c|}
\hline entry & $\begin{array}{c}\text { thio- } \\
\text { carbamate }\end{array}$ & product & $\begin{array}{l}\text { yield } \\
(\%)^{b}\end{array}$ & $\begin{array}{c}\text { endo/exo } \\
\mathrm{dr}^{\mathrm{c}}\end{array}$ & $\mathrm{er}^{\mathrm{d}}$ \\
\hline 1 & $1 \mathrm{~g}$ & $5 c$ & 67 & $84: 16$ & $96: 4$ \\
\hline 2 & $1 \mathrm{~g}$ & $5 d$ & 89 & $78: 22$ & $95: 5$ \\
\hline 3 & $1 \mathrm{~g}$ & $5 e$ & 98 & $90: 10$ & $97: 3$ \\
\hline 4 & 1f & $5 f$ & 56 & $95: 5$ & $18: 82$ \\
\hline 5 & $1 \mathrm{~g}$ & $5 g$ & 81 & $93: 7$ & $89: 11$ \\
\hline 6 & $1 \mathrm{~g}$ & $5 h$ & 62 & $80: 20$ & $91: 9$ \\
\hline 7 & 19 & $5 i$ & 55 & $85: 15$ & $96: 4$ \\
\hline 8 & $1 \mathrm{~g}$ & $5 \mathbf{j}$ & 81 & $93: 7$ & $98: 2$ \\
\hline 9 & $1 \mathrm{~g}$ & $5 k$ & 65 & $96: 4$ & $97: 3$ \\
\hline 10 & $1 f$ & 6 & 85 & - & $53: 47$ \\
\hline \multicolumn{6}{|c|}{$\begin{array}{l}\mathrm{a} \text { Reaction conditions: } \mathrm{BF}_{3} \cdot \mathrm{Et}_{2} \mathrm{O}\left(2 \text { equiv), } \mathrm{DCE}, \mathrm{MW}\left(150{ }^{\circ} \mathrm{C}\right), 10 \mathrm{~min} \text {. }\right. \\
\mathrm{b}^{\mathrm{b}} \text { Isolated yields }(\text { endo }+ \text { exo }){ }^{\mathrm{c}} \mathrm{dr} \text { measured by }{ }^{1} \mathrm{H} \mathrm{NMR} \text { and chiral } \\
\text { HPLC. er is measured by chiral HPLC from the endo major } \\
\text { diastereoisomer. }\end{array}$} \\
\hline
\end{tabular}

Surprisingly, the released chiral alcohol was not recovered at the end of the transformation. A carbocation is presumably generated from the alcohol in the presence

20 We suppose that $\mathbf{5 c - e}$ and $\mathbf{5 g}-\mathbf{k}$ have the same absolute configuration as $\mathbf{5 b}(4 S, 6 R)$. Major $5 \mathbf{f}$ should be of $(4 R, 6 S)$ configuration. of $\mathrm{BF}_{3} \cdot \mathrm{Et}_{2} \mathrm{O}$ which is subsequently involved in a polymerization with the alkene..$^{21,22}$ Although the inability to recycle the chiral alcohol represents a drawback of the method, the synthetic procedure is highly efficient, with an extremely simple purification step. Indeed, after the work-up, the product is precipitated in pentane and thus does not require separation from the chiral auxiliary by column chromatography.

To explain the asymmetric induction with $\mathbf{1 g}$ and $\mathbf{1 h}$, we hypothesize a stacked conformation (according to the $\mathrm{X}$-ray structure of $\mathbf{1 h}$ ), where the thiaazadiene and the phenyl (or naphthyl) ring are in front of each other. Thus, we suggest that the dienophile ${ }^{23}$ approaches the heterodiene by the less hindered front face, the back face being shielded by the aryl substituent on C-8 position of menthol (Fig. 2).

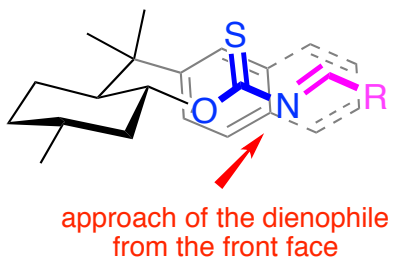

Figure 2. Transition state model for asymmetric induction

In summary, we have developed a new asymmetric efficient three-component domino reaction to synthesize chiral six-membered $N, S$-heterocycles with up to 98:2 er. The key step involves an asymmetric diastereoselective thia-HDA reaction, followed by the hydrolysis of the chiral auxiliary by in-situ generated water. The highly optical 2H-1,3-thiazin-2-one molecules obtained represent potential candidates for further synthetic and biological applications.

Acknowledgment. We acknowledge for financial support (grant for F.P.) the «Centre National de la Recherche Scientifique» (CNRS) and the "Région Basse-Normandie ». R. Legay and K. Jarsalé (LCMT) are acknowledged for the NMR analyses and mass spectra, respectively.

Supporting Information Available. Experimental procedures and compounds characterisation; X-ray data This material is available free of charge via the Internet at http://pubs.acs.org.

21 (a) Satoh, K.; Kamigaito, M.; Sawamoto, M. Macromolecules 2000, 33, 5830. (b) Chukicheva, I. Y.; Fedorova, I. V.; Koroleva, A. A.; Kuchin, A. V. Chem. Nat. Compd. 2008, 44, 450.

22 On the ${ }^{1} \mathrm{H}-\mathrm{NMR}$ spectra of the crude product obtained before work-up, characteristic signals of menthol were not present, but large peaks between 8 and 6 ppm et 3.5 and 1.5 ppm were observed. A similar spectra was obtained from an additionnal experiment, in which we reacted menthol, $\mathrm{BF}_{3} . \mathrm{OEt}_{2}$, and styrene.

${ }^{23}$ In the case of norbornene attacking via its exo-face, to release the sterical constrain due to the methylene bridge, the diene reacts probably in a different conformation, leading thus to the loss of selectivity. 